\title{
Role of hemofiltercytological tests in administration of adjuvant polychemotherapy for patients radically operated on for colon cancer and assessment of its effectiveness
}

\author{
AA Chimitov", Ya N Shoykhet ${ }^{2}$, AF Lazarev ${ }^{3}$, TD Khankhashanova ${ }^{1}$, OG Grigoruk ${ }^{3}$, Sabah Dhibi ${ }^{4,5 *}$, Elfeki A5 and Najla Hfaiedh ${ }^{4}$ \\ ${ }^{1}$ Buryat Regional Clinical Oncology Dispensary, Ulan-Ude, Russia \\ ${ }^{2}$ Altai State Medical University, Barnaul, Russia \\ ${ }^{3}$ Altai Regional Clinical Oncology Dispensary, Barnaul, Russia \\ ${ }^{4}$ Unit of Macromolecular Biochemistry and Genetics, Faculty of Sciences of Gafsa ,Faculty of Sciences, Sidi Ahmed Zarrouk, 2112, Gafsa, Tunisia \\ ${ }^{5}$ Laboratory of Environmental Physiopathology, Valorization of Bioactive Molecules and Mathematical Modeling, Faculty of Sciences Sfax, Road Soukra km 3.5, \\ PB no 1171-3000, Sfax, Tunisia
}

\begin{abstract}
Hemofiltercytological venous blood tests for patients radically operated on for colon cancer reveals circulating tumor cells (CTCs) in the early postoperative period. Their results serve as an indication for administration of adjuvant polychemotherapy to post-operative patients. The repeated hemofiltrocytological test on intensity of CTCs damages makes it possible to assess the quality and completeness of adjuvant polychemotherapy.
\end{abstract}

\section{Introduction}

The basic mode for colon cancer treatment is still the surgical one. However, surgery is not enough to provide satisfactory long-term results of treatment, because of coregional relapses and distant metastases that arise in the remote period. In connection with this, polychemotherapy is additionally used in treatment of patients with colon cancer $[1,2]$. Thus, according to the WHO, implementation of modern schemes of adjuvant polychemotherapy (XELOX, FOLFOX) in patients with colon cancer with regional metastases makes it possible to improve relapsefree survival in comparison with only surgical treatment in $10-20 \%$ [2]. One of the leading factors determining the outcome of the disease in patients with malignant neoplasms oncologists consider so-called circulating tumor cells (CTC), it is believed that they are never found in the blood and organs of people who has no malignant neoplasms [1]. It has been established that determination of CTCs in peripheral blood has an important prognostic significance and allows monitoring of the effectiveness of antitumor treatment [1].

At the same time, not only the initial quantity of CTCs is important, but also the dynamic changes in their quantity during the treatment. In the absence of CTCs decrease in patient's blood after chemotherapy the period before the disease progression was significantly shorter [3].

It is shown that the dynamics of CTCs amount correlates with the effectiveness of treatment of advanced breast, prostate, and colon cancer $[4,5,6]$.

\section{Materials and methods}

To improve the survival of cancer patients it is necessary to conduct adjuvant polychemotherapy after radical surgical treatment. Traditionally, local tumors are the indications for adjuvant polychemotherapy, as well as early stage 2 cancer in young people if there are unfavorable factors (low differentiation, vascular tumor invasion). However, the relapse-free and overall survival of the operated patients who undergone adjuvant polychemotherapy according to the above-mentioned indications leaves much to be desired. In connection with this, the search for new approaches to administration of adjuvant polychemotherapy does not stop.

In addition, until now there is no methods of quality control in adjuvant polychemotherapy, therefore to recognize its effectiveness in time in the case of drug resistance is not possible. Perhaps, this is the cause of unsatisfactory results of combined treatment for cancer patients. Accordingly, we need a method, which allows monitoring of adjuvant polychemotherapy at any stage.

To determine the indications for adjuvant polychemotherapy, we used hemofiltrocytological test (patent No. 2425385) of peripheral venous blood in patients radically operated on for colon cancer. For this purpose, we carried out venous blood microscreening of 145 patients, who underwent radical surgery twice, on the $15^{\text {th }}$ and $20^{\text {th }}$ days of the postoperative period, using the special device developed by us (patent No. 2414710). The device has calibrated filter with pores diameter 6000 nanometers.

Correspondence to: Sabah Dhibi, Unit of Macromolecular Biochemistry and Genetics, Faculty of Sciences of Gafsa, Faculty of Sciences, Sidi Ahmed Zarrouk, 2112, Gafsa, Tunisia, E-mail: s.dhibi@yahoo.fr

Key words: hemofiltrocytological test, adjuvant polychemotherapy, circulating cancer cells

Received: January 09, 2018; Accepted: January 27, 2018; Published: January 31, 2018 
Chimitov AA (2018) Role of hemofiltercytological tests in administration of adjuvant polychemotherapy for patients radically operated on for colon cancer and assessment of its effectiveness

We carried out the hemofiltrocytological test of peripheral venous blood in cancer patients with the help of this device. Before the test, the device for venous blood microscreening had been installed. At the bottom of a glass cylinder encased in plastic casing a plastic grid with calibrated filter fixed by metal ring was placed. On the eve, we had taken $6 \mathrm{ml}$. venous blood from ulnar vein of patients independently of eating into each of two Vacutainer tubes with anticoagulant EDTA (disodium ethylenediaminetetraacetic acid). On the day of the study, we assembled the device. At the bottom of the glass cylinder, encased in a plastic casing, a plastic grid was placed with a calibrated filter fixed to it with a metal ring.

To carry out a hemofiltrocytological test we poured $12 \mathrm{ml}$ of venous blood of the examined patient from the tube into the glass cylinder through the upper opening, while lower opening was in the closed position. A piston with a rod was inserted not against the stop into the glass cylinder.

The piston was moved to the level of liquid in the glass cylinder, and air from the cylinder was discharged through the channels in the piston with help of a metal ball acting as outlet valve.

Then we inserted the rod in the piston against the stop and thus the metal ball had been clamped (outlet valve was closed). Further, the device for lower outlet of the glass cylinder we put in the "open" position and all studied venous blood was passed through a calibrated filter; herewith tumor cells were kept in residue on the calibrated filter.

The residue was delivered to glass slides, previously degreased and cooled for better cell adhesion and drying. Smears were fixed by $3 \%$ Leishman's spirit solution in 2-4 minutes. Then they were rinsed by distilled water and dyed with azure-eosin mixture in 3:1 ratio for 6-8 minutes. After dyeing smears were rinsed by distilled water, dried in air and viewed under a microscope.

According to the results of tests, to all 108 patients with CTCs identified in their blood polychemotherapy was offered. 80 of them gave written consent to adjuvant polychemotherapy, and 28 patients refused. To determine the possible differences in the survival of these patients, two groups were formed. The main group included $80(74 \%)$ patients and compared group -28 (26\%) patients (Tables 1 and 2).
Only in the main group there were patients with colon cancer in stage T4a N0M0, and the largest number of oncological patients in both groups had stage T3 N2bM0. Both groups were comparable by stages and spread of the process.

The most common surgical operation for colon cancer was hemicolectomy. By extent of surgery the studied groups were comparable.

The statistical analysis hadn't find the significant differences in both groups of patients by disease stages and types of operations.

Thus, the indication for administration of adjuvant polychemotherapy for operated patients was carcinemia, i. e. detection of CTCs in venous blood after double hemofiltrocytological test, and their written consent.

Taking into account the presence of CTCs in peripheral venous blood of cancer patients on the $15^{\text {th }}$ and $20^{\text {th }}$ days after radical surgery (complete removal of the tumor along with the regional lymph nodes), it seemed necessary to carry out adjuvant polychemotherapy.

We used the following regimens of adjuvant polychemotherapy for colon cancer treatment.

\section{FOLFOX4}

2-hour oxaliplatin $85 \mathrm{mg} / \mathrm{m}^{2}$ IV infusion in $250-500 \mathrm{ml} \mathrm{D} 5 \mathrm{~W}(5 \%$ dextrose in water) on the $1^{\text {st }}$ day;

2-hour leucovorin $200 \mathrm{mg} / \mathrm{m}^{2} \mathrm{IV}$ infusion on the $1^{\text {st }}$ and $2^{\text {nd }}$ days;

5-FU (fluorouracil) $400 \mathrm{mg} / \mathrm{m}^{2}$ IV bolus on the $1^{\text {st }}$ and $2^{\text {nd }}$ days;

22-hour 5-FU $600 \mathrm{mg} / \mathrm{m}^{2}$ IV infusion on the $1^{\text {st }}$ and $2^{\text {nd }}$ days, 6 courses every 2 weeks.

\section{MAYO REGIMEN (5-FU/leucovorin)}

Leucovorin $20 \mathrm{mg} / \mathrm{m}^{2}$ IV bolus on the $1^{\text {st }}-5^{\text {th }}$ days;

5 -FU $425 \mathrm{mg} / \mathrm{m}^{2}$ IV bolus after administration of leucovorin on days 1-5.

Repeated chemotherapy in 3 weeks.

Table 1. Significance of differences in tumor spread in the studied groups of patients radically operated on for colon cancer

\begin{tabular}{|c|c|c|c|c|c|c|c|c|}
\hline \multirow{3}{*}{\multicolumn{2}{|c|}{$\begin{array}{c}\text { Disease } \\
\text { stage }\end{array}$}} & \multicolumn{4}{|c|}{ Groups of patients } & \multirow{3}{*}{$\mathbf{X}^{2}$} & \multirow{3}{*}{ f } & \multirow{3}{*}{$\mathbf{p}>$} \\
\hline & & \multicolumn{2}{|c|}{ Main } & \multicolumn{2}{|c|}{ Compared } & & & \\
\hline & & Abs. number & $\%$ & Abs. number & $\%$ & & & \\
\hline IIA & T3 N0M0 & 9 & 11,2 & 3 & 10,7 & \multirow{6}{*}{2,73} & \multirow{6}{*}{2} & \multirow{6}{*}{0,05} \\
\hline IIB & T4a N0M0 & 6 & 7,5 & 0 & 0 & & & \\
\hline IIIA & T2 N1M0 & 12 & 15,0 & 5 & 17,9 & & & \\
\hline IIIB & $\begin{array}{c}\text { T3 N1M0 } \\
\text { T4a N1M0 } \\
\text { T2 N2aM0 }\end{array}$ & $\begin{array}{c}10 \\
11 \\
7\end{array}$ & $\begin{array}{c}12,5 \\
13,8 \\
8,8\end{array}$ & $\begin{array}{l}3 \\
4 \\
2\end{array}$ & $\begin{array}{c}10,7 \\
14,3 \\
7,1\end{array}$ & & & \\
\hline IIIC & $\begin{array}{l}\text { T3 N2bM0 } \\
\text { T4a } 2 \text { aM0 }\end{array}$ & $\begin{array}{c}16 \\
9\end{array}$ & $\begin{array}{l}20,0 \\
11,2\end{array}$ & $\begin{array}{l}7 \\
4\end{array}$ & $\begin{array}{l}25,0 \\
14,3\end{array}$ & & & \\
\hline \multicolumn{2}{|c|}{ Total } & 80 & 100,0 & 28 & 100,0 & & & \\
\hline
\end{tabular}

Table 2. Significance of differences in types of surgical interventions in the studied groups of patients radically operated on for colon cancer

\begin{tabular}{|c|c|c|c|c|c|c|c|}
\hline \multirow{3}{*}{ Extent of surgery } & \multicolumn{4}{|c|}{ Groups of patients } & \multirow{3}{*}{$\mathrm{X}^{2}$} & \multirow{3}{*}{ f } & \multirow{3}{*}{$\mathbf{p}>$} \\
\hline & \multicolumn{2}{|c|}{ Main } & \multicolumn{2}{|c|}{ Compared } & & & \\
\hline & Abs. number & $\%$ & Abs. number & $\%$ & & & \\
\hline Hemicolectomy & 53 & 66,2 & 17 & 60,7 & \multirow{4}{*}{0,30} & \multirow{4}{*}{2} & \multirow{4}{*}{0,05} \\
\hline $\begin{array}{l}\text { Resection of the } \\
\text { transverse colon }\end{array}$ & 8 & 10,0 & 3 & 10,7 & & & \\
\hline Sigmoid resection & 19 & 23,8 & 8 & 28,6 & & & \\
\hline Total & 80 & 100,0 & 28 & 100,0 & & & \\
\hline
\end{tabular}


Chimitov AA (2018) Role of hemofiltercytological tests in administration of adjuvant polychemotherapy for patients radically operated on for colon cancer and assessment of its effectiveness

It should be noted that adjuvant polychemotherapy was administrated the oncological patients on the $30^{\text {th }}-40^{\text {th }}$ days after the radical surgery.

In addition to double detection of CTCs before adjuvant polychemotherapy hemofiltrocytological test had been carried twice more - during and after the treatment. Before the start of each next course of adjuvant polychemotherapy, one-time detection of CTCs was enough, but the rest two tests were required. Such a multiple hemofiltrocytological test serves for detection of CTCs, determination of the intensity of CTCs damages obtained due to the impact of chemotherapeutic agents, and the assessment of their viability. The absence of CTCs damages in the course of chemotherapy gives grounds to assume that the tumor is resistant to treatment and to change the regimen of adjuvant polychemotherapy.

\section{Results and discussion}

Cytological examination of smears obtained from the filtrate (blood) of 108 (74.4\%) patients operated on for colon cancer revealed the presence of CTCs. Negative results (absence of CTCs) had 37 $(25.5 \%)$ postoperative patients (Table 3 ).

In our opinion, a high percentage of postoperative patients, in whose peripheral venous blood we have detected CTCs, is associated with the fact that most of them have locally advanced stages of the disease.

The obtained due to the impact of adjuvant polychemotherapy damages of CTCs have been divided according to their intensity into four levels (I-IV) respectively to I-IV degrees of drug polymorphism.

Based on study of these cytograms, we have compared the levels of CTCs damages according to their intensity with standard degrees of drug polymorphism by the following features:

- at the level I of CTCs damages (degree I of drug polymorphism) cytomorphological changes in cancer cells are poorly expressed. Cancer cells are insignificantly polymorphic with focal dystrophic and necrobiotic changes. There are signs of mitosis;

- at the level II of CTCs damages (degree II of drug polymorphism) cytomorphological changes are moderately expressed. There was an intensification in polymorphism of cancer cells, an increase in dystrophic changes in the form of nuclei and cytoplasm vacuolization. There are no mitoses;

- at the level III of CTCs damages (degree III of drug polymorphism) cytomorphological changes are significantly pronounced. Cancer cells are characterized by a sharp polymorphism with the predominance of "bare" nuclei and pronounced signs of dystrophy, lysis, necrosis, the presence of cytoplasmic detritus;

- at the level IV of CTCs damages (degree IV of drug polymorphism) elements of malignant growth, i.e. circulating cancer cells, were not detected. The quality and completeness of adjuvant polychemotherapy, as well as drug resistance to one or another chemotherapy are assessed by the level of CTCs damages, comparable with a certain degree of drug polymorphism.

A statistically significant prevalence of the most pronounced levels III and IV of CTCs damages (degrees III-IV of drug polymorphism) over the least expressed damages of the levels I and II (degrees I-II) in malignant neoplasms of the large intestine was on average $30.0 \%$ (p < 0.001) (Tables 4 and 5).

The level I of CTCs damages (degree I of drug polymorphism) in blood of patients with colon cancer after chemotherapy was not observed.

The levels II and III of circulating cancer cells damages (degrees II-III of drug polymorphism) after chemotherapy are equally common in the cases of colon malignant neoplasms.

The level IV of CTCs damages (degree IV of drug polymorphism) was observed after chemotherapy for colon cancer in $20.0 \%$ of cases.

It is advisable to evaluate therapeutic polymorphism in addition to the clinical effect during any special treatment. Since hemofiltrocytological test allowing full morphological assessment of CTCs isolated from the blood with determination of the levels of their damage after adjuvant polychemotherapy, it is may be used for evaluation of therapeutic polymorphism. Moreover, patient's blood is the most accessible object for research.

To assess the effectiveness of complex treatment for radically operated patients with CTCs in peripheral blood, we compared overall survival depending on the course of post-operative chemotherapy.

The overall three-year survival in patients of the main group, who underment adjuvant chemotherapy, exceeded the results of the compared group with statistical significance $(p=0.0048)$ (Table 6).

Thus, it should be concluded that:

1) hemofiltrocytological test of peripheral venous blood of radically operated patients with colon cancer on the $15^{\text {th }}$ and 20th days after surgery makes it possible to detect circulating cancer cells;

Table 3. Frequency of CTCs detection in peripheral venous blood of radically operated oncological patients

\begin{tabular}{|c|c|c|c|c|}
\hline \multicolumn{2}{|c|}{ Total number of patients } & \multicolumn{2}{|c|}{ CTCs (+) } & \multicolumn{2}{|c|}{ CTCs (-) } \\
\hline Abs. number & \% & Abs. number & \% & Abs. number \\
\hline 145 & 100,0 & 108 & 74,4 & 37 \\
\hline
\end{tabular}

Table 4. Levels of CTCs damages (drug polymorphism) after chemotherapy

\begin{tabular}{|c|c|c|c|c|c|c|c|c|c|c|}
\hline \multirow{3}{*}{ Tumor site } & \multirow{2}{*}{\multicolumn{2}{|c|}{ Number of patients }} & \multicolumn{8}{|c|}{ Levels of CTCs damages (degrees of drug polymorphism) } \\
\hline & & & \multicolumn{2}{|c|}{ I } & \multicolumn{2}{|c|}{ II } & \multicolumn{2}{|c|}{ III } & \multicolumn{2}{|c|}{ IV } \\
\hline & Abs. number & $\%$ & Abs. number & $\%$ & Abs. number & $\%$ & Abs. number & $\%$ & Abs. number & $\%$ \\
\hline Colon & 80 & 100,0 & - & - & 28 & 35,0 & 36 & 45,0 & 16 & 20,0 \\
\hline
\end{tabular}

Table 5. Levels of CTCs damages in blood of patients of the main group after chemotherapy

\begin{tabular}{|c|c|c|c|c|c|c|}
\hline \multirow{2}{*}{ Tumor site } & \multicolumn{2}{|c|}{ Number of patients } & \multicolumn{3}{|c|}{ Levels of CTCs damages (degrees of drug polymorphism) } \\
\cline { 2 - 6 } & Abs. number & \% & Abs. number & \% & Abs. number & III-IV \\
\hline Colon & 80 & 100,0 & 28 & 35,0 & 52 \\
\hline
\end{tabular}


Chimitov AA (2018) Role of hemofiltercytological tests in administration of adjuvant polychemotherapy for patients radically operated on for colon cancer and assessment of its effectiveness

Table 6. Comparative analysis of three-year overall survival in patients with colon cancer

\begin{tabular}{|c|c|c|c|c|c|c|c|c|c|c|}
\hline \multirow{3}{*}{ Indicator } & \multirow{3}{*}{$\mathbf{n}$} & \multicolumn{9}{|c|}{ Groups of patients } \\
\hline & & \multicolumn{4}{|c|}{ Main } & \multicolumn{4}{|c|}{ Compared } & \multirow{2}{*}{$\mathbf{p}<$} \\
\hline & & Abs. number & $\%$ & Survival rate & $\pm \boldsymbol{\varepsilon}$ & Abs. number & $\%$ & Survival rate & $\pm \boldsymbol{\varepsilon}$ & \\
\hline $\begin{array}{c}\text { Three-year } \\
\text { overall survival }\end{array}$ & 108 & 80 & 74,0 & 1,00 & - & 28 & 26,0 & 0,86 & 0,12 & 0,005 \\
\hline
\end{tabular}

2) CTCs detected in peripheral venous blood of the postoperative patients are an indication for administration of adjuvant polychemotherapy;

3) hemofiltrocytological test of peripheral venous blood allows assessing the quality and completeness of adjuvant polychemotherapy.

\section{References}

1. Prorokov VV, Vlasov OA, Tupitsyn NN (2014) [Current state of the problem of treatment and prognosis of colorectal cancer]. Vopr Onkol 60:28-33. [Crossref]

2. Garin AM, Bazin IS (2010) Spravochnoe rukovodstvo po lekarstvennoi terapii solidnykh opukholei [Reference Guide for Drug Therapy of Solid Tumors]. Moscow: MAX Press, 2010. 368 p.

3. Bzhadug OB, Tjulandin SA, Grivtsova LYu, et al. (2007) The Prognostic Value of Circulating Tumor Cells in Blood of Patients with Advanced Breast Cancer Haematopoesis Immunology. 4: 73-101.

4. Cristofanilli M, Budd GT, Ellis MJ, Stopeck A, Matera J, et al. Circulating Tumor Cells, Disease Progression, and Survival in Metastatic Breast Cancer. N. Engl. J. Med. 2004. 351: 781-791. [Crossref]

5. Cohen SJ, Punt CJ, Iannotti N, Saidman BH, Sabbath KD, et al (2008) Relationship of Circulating Tumor Cells to Tumor Response, Progression-Free Survival, and Overall Survival in Patients with Metastatic Colorectal Cancer. J. Clin. Oncol. 26: 3213-3221. [Crossref]

6. de Bono JS, Tolcher AW, Rowinsky EK (2003) Farnesyltransferase Inhibitors and their Potential in the Treatment of Breast Carcinoma. Semin. Oncol. 2003. 30: 79-92. [Crossref] 